\title{
Modelos de Indicadores de Sustentabilidade: síntese e avaliação crítica das principais experiências
}

\section{Sustainability Indicators Models: synthesis and critical evaluation of the main experiences}

\author{
Flávio Tayra \\ Economista, Mestre em Economia, Doutor em Ciências Sociais e \\ Pós-doutorando em Saúde Ambiental, na Faculdade de Saúde \\ Pública, com apoio financeiro da Fapesp. \\ E-mail: ftayraœhotmail.com \\ Helena Ribeiro \\ Geógrafa, Mestre e Doutora em Geografia, Professora titular da \\ Faculdade de Saúde Pública daUSP. \\ E-mail: lenaळusp.br
}

\section{Resumo}

Neste artigo, buscamos realizar uma síntese, uma tentativa de categorização e uma avaliação crítica dos principais modelos, metodologias e experiências de construção de indicadores de sustentabilidade, destacando a necessidade da verificação e do estabelecimento de parâmetros e critérios em sua moldagem. $\mathrm{Na}$ atualidade, as principais experiências desenvolvidas ao redor do mundo, podem ser classificadas em dois tipos: 1) os chamados sistemas de indicadores, que seguem, em sua grande maioria, modelos derivados do Livro Azul da Comissão de Desenvolvimento Sustentável da ONU; e 2) os indicadores síntese, que buscam, em uma única unidade, agregar dados de ordem econômica, biofísica, social e institucional. Dentre tais tipos de indicadores, verifica-se uma grande diversidade de abordagens, com diferentes ênfases. Discutimos neste artigo a capacidade de tais indicadores efetivamente se converterem em marcos estruturados e cumprirem o seu papel de municiar, induzir e fomentar políticas e decisões bem estruturadas e fundamentadas.

Palavras-chave: Indicadores; Desenvolvimento sustentável; Vigilância ambiental. 


\section{Abstract}

In this article, we made a synthesis, a categorization attempt and a critical evaluation of the main models, methodologies and experiences of construction of sustainability indicators, attempting to verify and to establish parameters and criteria in their constitution. At the present time, the main experiences developed around of the world can be classified in two types: 1) the systems of indicators, derived from the model of the Blue Book of the Commission of Sustainable Development of UN; and 2) the indicators synthesis, that aim, in a single unit, to join data of economical, biophysics, social and institutional order. Among such types of indicators, a great diversity of approaches is verified, with different emphasis. We discuss in this article the indicators' capacity to induce and to foment policies and structured wellbased decisions.

Keywords: Indicators; Sustainable Development; Environmental Surveillance.

\section{Introdução}

Em nosso dia-a-dia estabelecemos e convivemos o tempo todo indicadores. Nós os utilizamos com tanta constância que, no mais das vezes, nem percebemos que o fazemos. Um bom exemplo foi utilizado por Wackernagel (1997): a temperatura do corpo humano. O que pode significar um termômetro assinalando a temperatura do corpo em $37,8^{\circ}$ ? Por meio de um dado simples, de obtenção quase imediata, se pode especular sobre os sintomas que uma pessoa está apresentando, indicando uma possível reação do corpo frente a uma dada situação. Sem essa indicação - não disponível com precisão há algumas décadas -, ficaria difícil caracterizar esta dada situação como um problema. Além disso, ela traz consigo uma gradação estabelecida que permite identificar a gravidade ou não do caso. Desta forma, uma oscilação, por exemplo, para $38^{\circ} \mathrm{C}$ indica alguma anormalidade, mas que não suscita maiores preocupações. Se esse indicador apontar $39^{\circ} \mathrm{C}$, cuidados mais específicos que demandam uma investigação aprofundada devem ser tomados.

A maior parte dos exames médicos busca dizer isso de alguma forma. Frente a um determinado quadro ou situação relativamente conhecida, um indicador ou um número (identificado com base em observações, pesquisas e situações pregressas) permite uma avaliação do quadro e os passos seguintes para o tratamento do paciente. A qualidade do indicador possibilita uma melhor ou pior avaliação e consequentemente delinear os rumos dos procedimentos com maior ou menor acuidade.

Mantendo o paralelo com a medicina, um indicador de sustentabilidade poderia ser comparado, por exemplo, a um exame de níveis de colesterol. Uma pessoa que apresenta um índice elevado pode - em muitos casos -, não estar ainda apresentando os sintomas do que pode vir a se constituir no futuro em uma situação temerária. Ainda que não esteja clara a situação num dado momento (em que ainda não se manifestaram as suas conseqüências), um exame prévio pode indicar uma situação de alta probabilidade de insustentabilidade no futuro; o que pode levar o paciente a rever seus hábitos pessoais e consequentemente mudar o diagnóstico futuro. Em muitos casos, a indicação pode conduzir a mudanças profundas de comportamento, a principal motivação para um exame prévio. 
Essa mesma preocupação atinge os indicadores de meio ambiente. Algumas estatísticas buscam retratar as condições de poluição (do ar, água, solo), de desmatamento, de perda de biodiversidade, entre outras. A partir de um determinado grau de poluição do ar, por exemplo, pode haver uma série de problemas de saúde pública. Verifica-se, no entanto, a dificuldade de se estabelecer tais parâmetros. Embora, em sua maioria, os indicadores permitam aferir a velocidade da ação - sua dinâmica de movimento -, em muitos casos não respondem a perguntas básicas como: Em que nível de degradação está? Determinada taxa é aceitável ou não? Sob quais condições? No curto, médio ou longo prazo?

Na tentativa do desenvolvimento sustentável, os indicadores revelam-se da maior importância, pois eles devem, conjugando-se os parâmetros ambientais aos sociais e econômicos, retratar e auxiliar na busca de soluções e políticas para a sua possível consecução. Os indicadores econômicos e sociais possuem uma história mais longa e, de certa forma, já podem ser considerados sedimentados. Os indicadores ambientais (de base biofísica) possuem história mais recente e ainda são passíveis de críticas quanto às suas metodologias de mensuração e gradação, e mesmo quanto aos seus significados. Ressalta-se, ainda, que os objetivos do desenvolvimento sustentável indicam a necessidade da variável institucional (a capacidade de organização social e de resposta política à questão) no trato do tema.

Num indicador de sustentabilidade, estes quatro fatores devem ser abarcados para que somados possam fornecer um quadro da situação abordada. A crise ambiental suscitada pelos debates tem nos mostrado que estão francamente interligados. Entre estes quatro aspectos, a quantidade de variáveis possíveis de serem incorporadas é imensa; identificar quais as mais importantes para uma melhor qualificação da realidade é uma dificuldade sempre presente. 0 peso e a importância de cada uma também são fatores a serem pensados. E entender como elas se relacionam entre si é o maior desafio.

$\mathrm{Na}$ atualidade, centenas de experiências de construção de indicadores, com diferentes modelos e abordagens, estão sendo conduzidas ao redor do mundo'. Neste artigo, nosso objetivo é realizar uma síntese, uma tentativa de categorização e uma avaliação crítica dos principais modelos e experiências, com o propósito de ressaltar a sua capacidade de efetivamente se converterem em indicadores de sustentabilidade e cumprirem o seu papel de municiar, induzir e fomentar políticas e decisões bem estruturadas e fundamentadas.

\section{Estado da Arte: classificação dos indicadores}

A partir do lançamento do conceito do desenvolvimento sustentável em meados da década de 1980 e sua popularização após a Conferência das Nações Unidas sobre o Meio Ambiente e Desenvolvimento (Rio-92), um dos principais desafios tornou-se a construção de instrumentos para sua mensuração, pois estes também seriam instrumentos essenciais para guiar a ação e subsidiar o acompanhamento e a avaliação do progresso alcançado rumo ao desenvolvimento sustentável.

A construção de Indicadores de Desenvolvimento Sustentável não é uma iniciativa isolada. É inspirada no movimento internacional, liderado pela Comissão para o Desenvolvimento Sustentável - CSD - das Nações Unidas, que reuniu, ao longo da década de 1990, governos nacionais, instituições acadêmicas, organizações não-governamentais, organizações do sistema das Nações Unidas e especialistas de todo o mundo². Este movimento, deflagrado a partir de 1992, pôs em marcha um programa de trabalho composto por diversos estudos e intercâmbios de informação, para concretizar as disposições dos capítulos 8 e 40 da Agenda 21, que tratam da relação entre meio ambiente, desenvolvimento sustentável e informações para a tomada de decisões.

10 site da International Institute for Sustainable Development contabilizava, em outubro de 2004, 624 experiências relatadas, com uma descrição com razoável riqueza de detalhes quanto aos seus objetivos, objetos e metodologia (http://www.iisd.org/measure/ compendium/searchinitiatives.aspx). A notificação ao site é feita de forma espontânea, o que indica que as experiências desenvolvidas devam ocorrer em um número ainda maior.

2 Em 1996, a CSD publicou o documento "Indicadores de desarollo sostenible: marco y metodologias" (1996), também conhecido como o "Livro Azul”. Este documento apresentou um conjunto de 134 indicadores, posteriormente reduzidos a uma lista de 57 indicadores apresentada no ano de 2000, acompanhada por fichas metodológicas e diretrizes para sua utilização. 
No processo de construção de indicadores de Desenvolvimento Sustentável, Quiroga-Martinez (2003) identificou três gerações:

a) Primeira geração: nesta fase, os indicadores eram os ambientais clássicos que não incorporavam interrelações entre os componentes de um sistema, como por exemplo: emissões de $\mathrm{CO}_{2}$, desmatamento, erosão, qualidade das águas, entre outros;

b) Segunda geração: os indicadores são compostos por quatro dimensões: econômica, social, institucional e ambiental, mas não estabelecem vinculações entre os temas. 0 maior exemplo desse tipo de iniciativa seria o Livro Azul da CSD (1996);

c) Terceira geração: são os indicadores que se tem buscado desde 1996, segundo Quiroga-Martinez (2003). Correspondem aos indicadores vinculantes, sinérgicos e transversais, que incorporam simultaneamente vários atributos ou dimensões do Desenvolvimento Sustentável. Não se tratam mais de listas de indicadores como os de segunda geração. As variáveis escolhidas têm que possuir correlação muito clara com os demais, pois fazem parte de um mesmo sistema.

Cabe lembrar que, antes mesmo da Rio-92, já haviam tentativas de construção de índices com inserção da variável ambiental nos indicadores econômicos. A experiência mais conhecida é a do IBES (Índice de bem-estar econômico sustentável), desenvolvida por Daly e Cobb (1989), que se aproximaria conceitualmente do que Quiroga-Martinez chamou de indicador de terceira geração.

$\mathrm{Na}$ atualidade, as principais experiências desenvolvidas ao redor do mundo podem ser classificadas em dois tipos: 1) os chamados sistemas de indicadores, que seguem em sua grande maioria, modelos derivados do "Livro Azul" e 2) os indicadores síntese, também conhecidos como comensuralistas, que buscam, em uma única unidade, agregar dados de ordem econômica, biofísica, social e institucional. Dentre tais tipos de indicadores, há uma grande diversidade de abordagens, com diferentes ênfases, enfocando aspectos monetários (como o PIB verde e a Poupança Genuína), sociais (como o ESI) e dados biofísicos (como a Pegada Ecológica), que serão detalhados a seguir.

\section{Sistemas de indicadores}

Sob o enfoque sistêmico, o objetivo dos sistemas de indicadores é a construção de um conjunto de indicado- res que mostrem tendências vinculantes e/ou sinérgicas, variáveis que analisadas em seu conjunto possam dar conta das principais tendências, tensões e causas subjacentes aos problemas de sustentabilidade.

As vantagens de tal enfoque decorrem de um certo consenso internacional que vigora em torno de tal modelo, por não requer comensurabilidade ou valoração (uma dificuldade sempre presente nos indicadores monetários, por exemplo). Como uma desvantagem, eles não conseguem revelar imediata ou sinteticamente os fenômenos. A sua construção é estimulada a partir de governos e organismos internacionais, o que tem lhes conferido uma grande aceitação mundial.

$\mathrm{O}$ mais popular dos sistemas de indicadores ambientais é o PER (Pressão-Estado-Resposta, PSR em inglês). $\mathrm{O}$ modelo foi desenvolvido e recomendado originalmente pela Organização para a Cooperação e Desenvolvimento Econômico (OCDE, 1993) e é também utilizado, com algumas alterações, por outras agências internacionais como Unstat (Divisão de Estatísticas das Nações Unidas) e Eurostat (Divisão de Estatísticas da Comunidade Européia).

De maneira geral, o modelo busca descrever a dinâmica de um problema ambiental; por exemplo, a pressão ambiental decorrente da deposição de esgotos em um rio ou a diminuição de área disponível para a vida selvagem. Tais pressões alteram o estado do sistema ambiental, reduzindo a qualidade da água ou a diversidade de espécies. Tais alterações, por seu turno, conduzem, em alguns casos, a respostas dos governos, ou das instituições (entre os quais, o próprio mercado). Medidas da condição do sistema podem ser enquadradas nestes três níveis; alguns argumentos têm sido apresentados para a necessidade de focalização nos indicadores de pressão, dado que eles permitem um alerta, gerando definição de políticas; mas, na prática, a maior parte dos indicadores se restringe ao nível de descrição de estado (Azar et al., 1996).

A abordagem PEIR (Pressão-Estado-Impacto-Resposta) é uma versão ampliada do modelo PER que vem sendo utilizada pelo PNUMA (Programa das Nações Unidas para o Meio Ambiente) na elaboração da série GEO (Global Environment Outlook). O projeto GEO, iniciado em 1995, busca avaliar o estado do meio ambiente nos níveis global, regional e nacional. A variável impacto busca mensurar o impacto ou o efeito produzido pelo estado do meio ambiente sobre diferen- 
tes aspectos, como os ecossistemas, qualidade de vida humana, economia urbana local, entre outros.

Hartmut Bossel (1999, p. 26) argumenta que estes tipos de indicadores (na realidade, listas de indicadores autônomos) possuem algumas deficiências: (1) elas são derivadas ad hoc, sem uma estrutura teórica conceitual que consiga refletir a operacionalidade e viabilidade da totalidade do sistema; (2) as escolhas sempre refletem as especificidades e a área de interesse de seus autores e: (3) como uma conseqüência de (1) e (2), eles tendem a ser densos em algumas áreas (múltiplos indicadores para uma mesma preocupação) e esparsos ou mesmo vazios em outras áreas também importantes.

Numa tentativa de maior sistematização, nos modelos PSR e PSIR, foram introduzidas algumas teorizações para sua aplicação em problemas relacionados ao desenvolvimento sustentável. Nesta aproximação, são identificadas cadeias isoladas de causa e efeito para um problema ambiental particular e são monitorados indicadores correspondentes. Por exemplo: emissões de $\mathrm{CO}_{2}$ (pressão) - concentração de $\mathrm{CO}_{2}$ da atmosfera (estado) - temperatura global (impacto) - imposto de carbono (resposta). A objeção mais séria para esta aproximação é que ela negligencia a natureza sistêmica e dinâmica dos processos que se encontra imersa em um sistema total muito mais amplo, em que as relações não possuem uma causalidade tão direta e exclusiva. Segundo Bossel (1999), a representação de cadeias de impacto através de PSIR é muito difícil de ser obtida e freqüentemente nem mesmo se constitui em uma aproximação adequada. Impactos em uma cadeia causal podem ser qualificados como pressão, e em outro podem ser identificados como estado, e vice-versa. Não são considerados pressões múltiplas e impactos.

As relações não-lineares entre os componentes diferentes de uma cadeia não podem ser consideradas neste modelo. Por exemplo, uma cadeia de PSIR, representando o problema de emissões de $\mathrm{CO}_{2}$, não responderia pelo fato de que a concentração de $\mathrm{CO}_{2}$ é apenas parcialmente causada pelas emissões decorrentes de atividades antrópicas, assim como a temperatura global é também apenas parcialmente determinada pelas emissões de $\mathrm{CO}_{2}$. Além disso, a introdução de um imposto sobre carbono pode ter outras razões que não seja a redução de emissões; fato adicional, tal imposto teria outras repercurssões (econômicas e sociais), além de simplesmente afetar emissões de CO2. (Bossel, 1999).

Em 2003, o PNUMA publicou metodologia para a elaboração de informes GEO Cidades, para avaliação do meio ambiente local. A metodologia GEO consiste em uma avaliação ambiental que procura responder a seis perguntas básicas:

1. O que está ocorrendo com o meio ambiente?

2. Por que está ocorrendo?

3. Qual o impacto?

4. O que está se fazendo em termos de políticas ambientais?

5. O que poderá acontecer se não for feito nada?

6. 0 que pode ser feito para reverter tal situação?

A metodologia do GEO é um instrumento analítico que permite organizar e agrupar, de maneira lógica, os principais fatores que atuam sobre o meio ambiente. A partir dele estão se construindo indicadores urbano-ambientais em várias partes do mundo.

Em São Paulo, a prefeitura do município também se organiza atualmente para a elaboração de seu sistema de informações (Prefeitura do Município de São Paulo, 2004). A tentativa paulistana de construção do sistema contempla, no total, 83 indicadores: 23 indicadores de pressão sobre o meio ambiente (como crescimento e densidade populacional, produção de resíduos sólidos, ocorrências contra a fauna); 20 indicadores de estado do meio ambiente (como qualidade do ar, efeito estufa, chuva ácida); 19 indicadores de impacto sobre a saúde humana e meio ambiente (incidência de enfermidades associadas à poluição do ar, índice de vulnerabilidade juvenil, desvalorização imobiliária...); e 21 indicadores de respostas da sociedade (dados como controle de emissões atmosféricas, investimentos em água e esgoto, ampliação de cobertura vegetal...).

Quando se concebe um sistema de informações de tal magnitude, um problema recorrente é o da obtenção de dados. Em muitos casos, eles não estão disponíveis na escala desejada ou, simplesmente, não existem, ou ainda pior, possuem qualidade duvidosa; o que certamente compromete a capacidade de o sistema prover informações fidedignas sobre a real situação do espaço analisado. Um outro problema é o da escolha de variáveis; a metodologia GEO certamente deu maior consistência às escolhas específicas de cada 
espaço. Ela colabora no sentido de prover bases teóricas para a escolha; mas, sua adoção pura e simples pode esconder a necessidade de uma grande discussão a respeito de tais escolhas.

Uma experiência importante de construção de sistemas de indicadores foi realizada pela cidade de Seattle (EUA), a partir de 1991. Apenas cinco anos depois, o projeto "Seattle Sustentável" conseguiu atingir o seu objetivo de montar um sistema de informações compatível com os objetivos pretendidos. Muitas discussões foram feitas, com realização de congressos, simpósios com especialistas e reuniões com a comunidade para definir os indicadores. Em uma primeira tentativa, o sistema de informações sugeriu 99 indicadores diferentes. Após reflexão e amadurecimento, percebeu-se que era um número exagerado; por conseqüência, pouco operacional ou visível. $\mathrm{Na}$ versão final do sistema, o número de indicadores utilizados havia sido reduzido para 40 (Sustainable Seattle, 1998).

Após a experiência de Seattle, várias cidades ao redor do mundo iniciaram a elaboração de seu sistema de indicadores. 0 site da IISD (International Institute for Sustainable Development), na página Compendium: a global directory to indicator initiatives, traz uma lista de 619 modelos de indicadores que estão sendo elaborados (ou já se encontram elaborados) ao redor do mundo (apenas os que reportaram suas atividades ao site) ${ }^{3}$. Entre estes, encontram-se centenas de cidades que estão construindo seus sistemas nos moldes dos realizados por Seattle.

Embora já existam experiências bem-sucedidas e uma metodologia estabelecida por organismo da ONU, é possível perceber em propostas de índices e indicadores de sustentabilidade, alguns problemas comuns aos indicadores até então construídos, como: ausência ou fragilidade da concepção conceitual, fragilidade dos critérios de escolha das variáveis representativas, falta de critérios claros de integração dos dados, baixa relevância dos dados utilizados.

Segundo Braga et al. (2003, p. 7), devido à falta de precisão nos conceitos de sustentabilidade e qualidade ambiental, o processo de escolha dos dados e das variáveis a serem utilizadas na mensuração dos refe- ridos fenômenos é, às vezes, pouco claro, assim como as relações de causalidade que dão suporte aos sistemas de indicadores construídos. Muitos dos assim denominados sistemas de indicadores são, muitas vezes, meras listas de dados e variáveis. Por se tratarem de iniciativas isoladas, em geral restritas a um contexto local, a comparabilidade dos indicadores e índices é geralmente baixa. A construção dos índices envolve ainda a dificuldade de tornar comparáveis dados de diferentes fontes, produzidos a partir de escalas distintas, com cobertura e distribuição espacial e temporal diversas, levando à busca de formas alternativas e aproximadas para imputar dados faltantes e construir proxys adequadas e representativas de informações inexistentes.

\section{Indicadores síntese}

A motivação para a construção de modelos síntese, que possibilitam condensar em um único número a situação ambiental, se baseia na percepção que se moldou a partir da popularização de indicadores econômicos como o PIB (Produto Interno Bruto) ou a taxa de inflação. Como já salientado, ainda que suas construções não sejam compreensíveis para a maioria das pessoas, tanto o PIB como taxa de inflação acabaram por se tornar medidas usuais nos debates sobre o desempenho econômico, sendo universalmente reconhecidos e entendidos.

Da mesma forma, para um bom número de pessoas, políticos e mesmo cientistas entre eles, se coloca a necessidade de elaboração de um indicador ambiental unificado que sirva de base para a tomada de decisões. 0 sucesso do PIB e da taxa de inflação demonstra o papel que indicadores ambientais amplamente aceitos poderiam desempenhar na avaliação do sucesso das políticas e na responsabilização de quem as elabora. Alguns chegam a afirmar que a inexistência de um indicador ambiental equivalente tende a reduzir a importância do meio ambiente na elaboração das políticas.

Os que defendem o modelo síntese enfatizam que um indicador deste tipo poderia melhor indicar uma tendência global e teria um maior poder para influenciar a opinião pública, promovendo uma maior mobi-

\footnotetext{
3 Para maiores detalhes sobre as iniciativas de construção de indicadores ao redor do mundo, o endereço do site é http://www.iisd.org/ measure/compendium/searchinitiatives.aspx, acessado em 13.07.2004.
} 
lização e direcionamento de recursos públicos e privados voltados à obtenção da sustentabilidade. Como uma aproximação, seria mais útil que uma extensa gama de dados integrando um sistema de indicadores. Embora menos preciso, seria muito mais compreensível para o público geral (embora provavelmente possa não compreender a sua estrutura de construção, como no caso do PIB ou da medição da inflação).

A crítica mais comum que se coloca a este modelo é a de que, ao agregar diversos indicadores ambientais em uma única medida, acaba por insinuar trade-offs que podem não existir na realidade, além agregarem dados de assuntos irreconciliáveis em uma unidade comum de medida. Para Vitalis (2001), o mesmo tipo de restrição foi colocado, inicialmente, para o uso do PIB. No momento inicial, muitos países resistiram à sua implementação e denunciaram a medida pela sua simplicidade, sua dificuldade em exprimir trade-offs adequadamente, e até mesmo criticaram a sua pretensão em medir crescimento econômico global com precisão.

O PIB encontra grandes dificuldades para retratar adequadamente certos aspectos (como a mão-deobra doméstica e os gastos defensivos) e não possui uma correspondência direta com o nível de bem-estar. Apesar disso, é um dos principais instrumentos para a análise e desenvolvimento de políticas. Sua utilidade permanece porque é prontamente entendido pelo público em geral, é amparado em uma metodologia sólida e provê uma boa indicação do estado da economia em termos de economia global, além de conseguir ilustrar, com clareza, o movimento tendencial da economia no decorrer do tempo.

Em uma época em que há preocupação crescente sobre a saúde do ambiente em particular, e sobre sustentabilidade, em geral, é extremamente importante que os formadores de política disponham de um indicador que comunique, de forma clara e efetiva, à opinião pública, informação concisa sobre tendências globais em sustentabilidade (Vitalis, 2001). A importância é clara, o que não acontece com os procedimentos para a sua elaboração e construção.

Entre os indicadores síntese, pode-se observar os que agregam em termos de índice e os que o fazem em termos de unidades monetárias, físicas ou energéticas. Alguns dos principais exemplos:

\section{Monetizados}

Existe uma grande dificuldade na elaboração dos indicadores monetizados; dificuldade que reside basicamente na quase impossibilidade de atribuição de valores e preços corretos aos bens naturais. A despeito disso, existem várias tentativas de construção. Os indicadores monetários comensuralistas mais conhecidos são o PIB Verde (sua tentativa de construção), a Poupança Genuína e o Indicador de Progresso Genuíno.

As críticas já mencionadas aos sistemas de contas nacionais para o cálculo do PIB têm instigado tentativas de modificação na Contabilidade Nacional, regulada no mundo todo pela ONU. A idéia inicial era estimar um PIB Verde, que incluiria danos e serviços ambientais, assim como as mudanças nos estoques de capital natural. Mas, as dificuldades de valoração conduziram esses esforços para a construção de contas satélites, à margem das nacionais, para incluir nelas a perspectiva ambiental. 0 primeiro marco global para a contabilidade ambiental foi proporcionado pela ONU (Green Accounts System of Environmental and Economic Accounts). No princípio, custos e benefícios ambientais, ativos baseados em recursos naturais e proteção ambiental, são todos apresentados em termos de fluxos e estoque. 0 problema é a dificuldade de fazer comparações entre contas em diferentes unidades para avaliar prioridades e relações.

Alguns bens, como a madeira, podem ter valor de mercado, mas esse valor não abrange o papel da árvore como hospedeira de besouros raros ou como dona de uma beleza exuberante. Uma das diretrizes para contornar tal problema é mensurar o custo da reparação ao estrago (os gastos defensivos); alguns tipos de danos, como a extinção é, por exemplo, de difícil custeamento. Um problema adicional: em termos econômicos, o valor médio de um bem ou serviço é geralmente menos importante que o valor marginal - o custo ou benefício de mais uma unidade. 0 valor marginal é, contudo, um conceito difícil de ser incluído na análise ambiental. A extinção de uma espécie de uma espécie de besouro presumivelmente deve ter um custo alto (ainda que de difícil mensuração), mas qual seria o valor agregado da matança de algumas centenas de besouros?

Segundo definição do Banco Mundial (QuirogaMartinez, 2003), a poupança genuína é a poupança nacional após a dedução da depreciação de recursos 
naturais e os danos por contaminação, assim como a contabilização positiva do investimento em capital humano. A idéia de poupança genuína deveria ser, em relação ao capital total, o equivalente à de poupança interna líquida dentro da contabilidade nacional, referente aos fluxos resultantes das atividades produtivas. A preocupação essencial, implícita na noção de poupança genuína, é a consideração de que os custos totais das ações de produção, em seu sentido mais amplo (incluindo os efeitos de certos consumos finais), tratam de internalizar os impactos relativos ao patrimônio natural e de incorporar as variações que afetam o capital humano.

A poupança genuína é considerada um indicador de sustentabilidade fraca, ou seja, parte da idéia de que, para conseguir o desenvolvimento sustentável, é necessário garantir o estoque total de capital incluindo não somente o capital natural, mas também o elaborado pelo homem. Se um país não poupa o suficiente para compensar a depreciação do capital natural, não estará seguindo um caminho de sustentabilidade, ou, se uma economia acumula capital a uma taxa maior à que destrói, ela segue mantendo a capacidade de gerar bem-estar no futuro. Para que a capacidade produtiva total de um sistema econômico não diminua, ou cresça, é necessário que o nível de poupança de uma economia seja igual ou maior do que a soma do valor da depreciação do capital manufaturado.

O calculo da poupança genuína incorpora dados de educação, energia, minerais, recursos florestais e emissões de gás carbônico. Em educação, são utilizados dados de despesas para avaliar o grau de investimento em capital humano; energia compreende petróleo, gás natural e carvão; minerais incluem bauxita, cobre, ouro, ferro, diamante, níquel, fosfato, lata, prata e zinco; recursos florestais incluem madeiras naturais e tratadas, não sendo avaliados produtos florestais que não sejam madeira; e as emissões de gás carbônico mensuram dados de combustão de combustíveis fósseis e fábricas de cimento.

Segundo Hamilton (2001), se taxas de poupança são baixas ou negativas, a sustentabilidade do caminho de desenvolvimento é marginal ou duvidosa, sob a política vigente. Taxas de poupança crescentes requerem o cardápio habitual de políticas macroeconômicas, mas também podem incluir os recursos humanos e ministérios de saúde (para o capital humano), a ciência e ministério de tecnologia (construindo conhecimento e tecnologia), o ministério de recursos naturais (para assegurar taxas eficientes de extração de recursos naturais e níveis eficientes de danos de poluição).

Para chegar ao indicador de poupança genuína, é preciso valorar monetariamente a utilização de parte do estoque de capital natural (minerais, petróleo, gás e madeira, mas, por dificuldades de valoração, não inclui ativos como água, pesca e solo) e também o dano por contaminação ambiental.

O Indicador de Progresso Genuíno (GPI - Genuine Progress Index) deduz alguns fatores utilizados no cálculo do PIB, tendo em conta critérios sociais e ambientais, além dos aspectos estritamente econômicos. Assim como no PIB, o GPI começa com gastos com consumo das pessoas, mas busca avaliar o seu bemestar, ao invés de focar exclusivamente nos recursos financeiros gastos. Enquanto o PIB adiciona os gastos com despesas e investimento do governo, o GPI considera tais gastos defensivos.

As despesas de consumo pessoais são ajustadas para distribuição de renda pelo coeficiente de Gini. Segundo Cobb et al (1999), nos EUA, de 1973 a 1993, enquanto o PIB subiu cerca de $55 \%$, os salários reais declinaram cerca de 3,4\%. Nos anos 1980, a parcela dos $20 \%$ mais pobres da população perdeu o, $5 \%$ de sua renda por ano, ao passo que os $5 \%$ mais ricos aumentaram sua renda em cerca de 3,9\% ao ano. Ou seja, o crescimento não beneficiou todo mundo, e uma verdadeira medida de bem-estar deveria levar em conta esta desigualdade. Usando despesas de consumo pessoais ajustadas para desigualdade de renda como sua base, o GPI soma ou subtrai categorias de gastos baseado na sua capacidade em aumentar ou diminuir o bem-estar do país.

Ignorado no PIB, o GPI inclui os seguintes benefícios não monetários: a) o valor do tempo gasto em trabalho doméstico, familiar ou voluntário; b) o valor de serviço de bens de consumo duráveis (como carros e refrigeradores); e c) serviços de rodovias e ruas. Por outro lado, subtrai categorias de despesas que não melhoram o bem-estar, como: a) despesas defensivas, definidas como dinheiro gasto para manter o nível de conforto, segurança, ou satisfação, devido a declínio de qualidade de vida por conta de aspectos como aumento do crime, acidentes de automóvel, ou poluição. 
Exemplos incluem filtros de água pessoais, fechaduras ou sistemas de segurança, gastos com hospital, ou o custo de repintar a casa, por conta de poluição do ar; 2) custos sociais, como o custo de divórcio, crime, ou perda de tempo de lazer; 3) depreciação de ativos ambientais e recursos naturais, inclusive perda de terra cultivada e florestas, redução de estoques de recursos naturais, como combustíveis fósseis; e efeitos prejudiciais de lixo e poluição.

Esta operação mostrou que, ainda que o PIB nos EUA tenha aumentado $37 \%$ entre 1980 e 1998 , o GPI diminuiu cerca de $24 \%$, uma vez que traz consigo uma degradação da qualidade de vida dos seres humanos, mostrando que as práticas econômicas vigentes, ao buscar somente um benefício monetário imediato, podem ignorar possíveis conseqüências futuras.

\section{Índices}

Entre os índices comensuralistas mais populares estão o IBES (já mencionado), o LPI (Living Planet Index), o ESI (Environmental Sustainability Index) e Indicador de Pegada Ecológica (Ecological footprint Ecofootprint)

O IBES foi concebido por Daly \& Cobb (1989) primeiramente para analisar a evolução da economia dos EUA. Com dados dos EUA, para o período de 1950 a 1986, Daly e Cobb (1989) chegaram à conclusão de que o crescimento anual do PIB per capita foi de 1,9\% ao passo que para o IBES, foi de apenas $0,53 \%$.

O IBES tem como ponto de partida o consumo pessoal. Inicialmente, o consumo pessoal é corrigido para efeitos de distribuição de renda. Uma vez que o consumo pessoal é modificado pelos efeitos distributivos, se somam alguns serviços que não passam pelo mercado (como o trabalho doméstico que não é remunerado) e outros que passam pelo mercado como o valor dos serviços que provem de consumos duráveis e a proporção de gastos do governo com saúde e educação, considerados não defensivos e que visam o aumento do bem-estar. Posteriormente, são retirados os gastos do governo em saúde e educação, tidos como defensivos, os custos sociais e ambientais (como acidentes de automóvel e contaminação do ar e solo) e a perda de capital natural (terras agrícolas, esgotamento de recursos não-renováveis e renováveis e os danos ambientais de longo prazo).

A forma como são calculados muitos dos componentes do IBES é bastante polêmica e tem sido aber- tamente exposta por seus próprios autores. O cálculo implica monetizar uma série de custos ambientais (água, ar, ruído...), assim como o esgotamento de capital natural (renováveis e não-renováveis), e os danos ambientais de longo prazo. Estes cálculos enfrentam os usuais problemas técnicos de valoração dos bens e serviços ambientais que não passam por mercados convencionais.

O Living Planet Index (LPI), elaborado pelo Fundo Mundial para a Natureza (WWF), é uma medida de saúde dos ecossistemas globais e de biodiversidade, com base em dados que mostram as mudanças através do tempo no estado dos bosques (cobertura natural em todo o mundo), espécies de água doce e população de ecossistemas marinhos. Trata-se de uma tentativa de quantificar a extensão e severidade da perda de biodiversidade.

O ESI (Environmental Sustainability Index) foi elaborado pelo Yale Center for Environmental Law and Policy e Center for International Earth Science Information Network, (Ciesin) da Universidade de Columbia. Ele foi apresentado no Fórum Econômico Mundial de Davos, no principio de 2001, e desde então vem sofrendo ajustes. 0 índice condensa 22 indicadores ambientais que vão desde qualidade do ar, redução de dejetos, até a proteção de bens comuns internacionais. A classificação obtida por cada país é desagregada em 67 matérias específicas, como a medição de dióxido de enxofre no ar urbano e mortes associadas às más condições sanitárias.

Segundo Braga et al (2003), o ESI constrói um ranking de países a partir de um amplo conjunto de indicadores relativos a desenvolvimento e meio ambiente, passíveis de comparação entre um número significativo de países. Também evidenciam que a análise comparativa no âmbito ambiental pode identificar sucesso ou falhas de intervenções políticas e chamam a atenção para a carência de informações ambientais de qualidade no mundo e para a urgência de investimentos em sistemas de monitoramento ambiental e produção de séries temporais de dados para parâmetros e variáveis chave.

Os críticos do ESI alegam que ele pouco contribui no sentido de prover informações para o longo prazo. Ao considerar 67 variáveis, ele não distingue a importância que cada uma delas possa ter para os diferentes espaços físicos ao redor do mundo. Além disso, não 
pondera nenhuma das variáveis: degradação de terra, disponibilidade de água, déficit ecológico e taxa de fertilidade são consideradas iguais a preços de petróleo e medidas de corrupção política.

Uma das primeiras tentativas de mensurar o impacto humano per capita no meio ambiente foi desenvolvida pela metodologia da Pegada ecológica (Ecological footprint), proposta por Wackernagel e Rees (1996). A pegada ecológica é uma medida de carga imposta por uma população sobre a natureza. Ela representa a área de solo que é requerida para sustentar os níveis atuais de consumo dos recursos e geração de dejetos de tal população, expressa em unidades de hectare por pessoa. Uma constatação da pegada ecológica é que o grau de exploração de recursos naturais e produção de rejeitos depende, em grande medida, dos padrões de consumo das sociedades.

A pegada ecológica se inclui dentro da categoria de sustentabilidade forte, que propõe uma mudança radical na atitude da sociedade e de modelo econômico, para um que seja pautado no ecológico e na qualidade de vida, respeitando os limites da natureza, ou sua "capacidade de carga". 0 cálculo da pegada se baseia em cinco suposições:

1. É possível seguir a pegada da maioria dos recursos que as pessoas consomem, assim como muito dos dejetos que produzem. Grande parte dessas informações pode ser encontrada nas estatísticas oficiais existentes; 2. A maior parte desses recursos e resíduos pode ser convertida em área biologicamente produtiva necessária para manter os fluxos; 3. As áreas necessárias se expressam na mesma unidade (hectares ou acres globais) e se relacionam proporcionalmente à produtividade de biomassa. Em outros termos, cada unidade corresponde a um hectare de espaço biologicamente produtivo e se expressa como "produtividade média mundial"; 4. Uma vez que estas áreas representam usos exclusivos e cada hectare representa uma quantidade produtiva de biomassa, elas se somam ao total que reflete a demanda humana; 5. A área para a demanda humana total pode ser comparada à oferta ambiental, uma vez que também é possível avaliar a área biologicamente produtiva do planeta.

O cálculo da pegada ecológica (que divide a área total de terrenos produtivos da Terra pela população mundial) disponibiliza o valor de 1,9 ha per capita (incluindo o uso dos oceanos e compartilhando-o com mais 30 milhões de espécies). A média mundial da pegada, no entanto, já é de 2,3 ha (sendo que nos países desenvolvidos a média é superior a 5 ha), ou seja, já superamos os limites da insustentabilidade em quase $40 \%$ (WWF, 2002). 0 dado, para muitos autores considerado impreciso, mostra uma utilização das áreas superior à capacidade de carga do planeta, determinando o que os autores da metodologia chamam de déficit ecológico.

O que significaria uma utilização dos recursos naturais do planeta da ordem de $40 \%$ acima da sua capacidade? Por quanto tempo poderia perdurar tal situação? Um aspecto que deve ser considerado é que a pegada ecológica varia com relação ao tamanho da população, à média de consumo por pessoa, à intensidade de uso dos recursos e também à capacidade do homem em construir artifícios para reutilizar os recursos e tratar os resíduos e dejetos do processo, aspecto não abordado na metodologia. A tecnologia teria, nesse sentido, o duplo papel de poder alterar a produtividade ou a eficácia com que os recursos são utilizados para produzir bens e serviços e também para elaborar aparatos que mitiguem a geração de resíduos, além de possibilitar a montagem de equipamentos que auxiliem a natureza em sua capacidade de re-assimilação.

Desta forma, a metodologia é bastante útil para atentar para a intensidade da utilização dos recursos naturais do planeta, o que faz, para seus autores, de forma conservadora. No que se refere à capacidade de suporte do planeta para fornecer tais recursos e assimilar os resíduos e dejetos e regenerar os sistemas -, a metodologia parece não reconhecer o seu caráter dinâmico e evolutivo, como alegam vários cientistas.

\section{Algumas conclusões sobre os indicadores de sus- tentabilidade}

$\mathrm{Na}$ atualidade, existem muitas iniciativas de construção de indicadores de sustentabilidade, mas, em sua grande maioria, as variáveis não se encontram necessariamente integradas e ordenadas, a não ser para responder temas bem específicos (por exemplo, qualidade de água e do ar, biodiversidade ou desertificação), e geralmente em escala local. Os indicadores de nível regional, ou nacional, ainda requerem um grande esforço para apresentarem agregação, harmonização e regionalização dos dados que alimentam os indicadores. 
Apesar disso, já é possível observar o estabelecimento de alguns critérios para a constituição do que venha a ser considerado um bom indicador. A OECD (1998) estabeleceu alguns critérios de seleção de indicadores de meio ambiente, sob três aspectos principais: relevância política, clareza analítica e mensurabilidade.

Em todo o mundo, há um claro processo de desenvolvimento conceitual, metodológico e instrumental. Quiroga-Martinez (2003) destaca que as experiências compreendem tentativas que utilizam escalas diversas (nacional, estadual, municipal...) e enfoques metodológicos bastante diferentes entre si. Alguns países buscam indicadores de sustentabilidade ambiental, enquanto outros procuram construir indicadores de desenvolvimento sustentável, englobando (mas não necessariamente vinculando) dimensões econômica, social, ambiental e institucional. No entanto, a revisão de literatura mostrou que as principais experiências de construção de indicadores se voltam ao âmbito municipal. Inúmeras cidades de vários portes já realizam ou se organizam para construir seus sistemas de informação para o desenvolvimento sustentável.

Tais sistemas de informações (sistemas de indicadores) são ferramentas muito importantes para a avaliação do estado local. Seriam ainda mais importantes se os seres humanos modernos não tivessem desenvolvido uma característica típica dos dias atuais, o que os economistas usualmente chamam de "trocas com o setor externo" ou ainda "relações com o resto do mundo". As economias modernas, os municípios incluídos, se caracterizam por serem sistemas abertos, com entrada e saída de recursos. Com isso, as necessidades dos espaços locais podem ser supridas, em muitos casos, principalmente por recursos extraídos em regiões muito distantes de seu local de consumo.

Em sistemas naturais habitados somente por animais, quando existe um excesso de consumo de seus recursos locais, motivados por excesso de população ou mesmo algum desequilíbrio de ordem física (enchentes e secas, por exemplo) o que ocorre é um reequacionamento da demanda, com ocorrência de diminuição da população por morte ou migração, numa demonstração de que tal espaço não comporta determinada quantidade de indivíduos a um certo nível de consumo per capita.

Nas comunidades humanas - com a sua evolução-, tal situação pode ser mitigada de várias formas, principalmente com a importação de recursos de outros espaços. A sociedade moderna desenvolveu tal característica ao extremo. Nas grandes cidades atuais, como São Paulo, a preocupação ambiental é principalmente com a capacidade de o espaço local absorver e re-assimilar os dejetos do processo (toda sorte de lixos, resíduos e esgotos). Quase toda a sua alimentação (água incluída), recursos para a produção e bens de consumo são importados de outros locais. Se os paulistanos tivessem de se alimentar somente com o que estivesse disponível em suas terras, provavelmente já estariam extintos.

Numa cidade desse porte, "metade" das preocupações ambientais é transferida para outros locais por meio da importação de recursos naturais provenientes de outras regiões do mundo. Dessa forma, ela não precisa se preocupar com a sua escassez de recursos, apenas com a capacidade de re-assimilação dos dejetos de sua produção e consumo; o que não é pouca coisa, pois a entrada de recursos externos no seu espaço é muito maior do que a quantidade que naturalmente dispõe, e o seu meio ambiente não está plenamente adaptado para absorver proporcionalmente tamanha quantidade de resíduos.

Quanto ao desenvolvimento de indicadores-síntese (sintéticos) - ou comensuralistas -, a dificuldade é ainda maior, pois eles envolvem uma clara necessidade de ponderação de variáveis. Uma notável exceção é o ESI que, reconhecendo tal dificuldade, simplesmente abdicou da realização da atividade de atribuir pesos diferentes às diferentes variáveis. Tal tipo de indicador possui metodologia muito mais complexa e é de difícil adaptação a cenários locais, na maioria dos casos, embora permita visualizar, com muito maior facilidade, a situação ambiental ou de sustentabilidade.

A metodologia da Pegada Ecológica (Ecofootprint), por exemplo, que é bastante conhecida internacionalmente, sofre severas críticas e também está longe de ser considerada um consenso na área, por conta das proposições e ponderações assumidas em sua concepção. As tentativas de construção do PIB Verde, bastante popular na década de 1990, também encontram grandes dificuldades práticas, basicamente em virtude da dificuldade de atribuição de valores a bens não transacionados no mercado (Hamilton, 2001). A despeito de suas dificuldades técnicas, demonstra uma 
percepção/tentativa com uma clara opção pela visão de que o mercado consegue, por si só, reaver um equilíbrio entre a atividade antrópica e o meio ambiente.

Apesar das críticas recorrentes, a produção e o acesso aos dados e informações ambientais estão melhorando, embora continuem apresentando deficiências. Ainda se dispõem, por exemplo, de poucas informações sobre os impactos ambientais na saúde humana e nos ecossistemas naturais. A falta de dados e a qualidade duvidosa de outros prejudicam muito a avaliação integral pretendida. A infraestrutura de obtenção de dados e monitoramento de processos em muitos locais (principalmente nos países, regiões e municípios mais pobres) são muito difíceis (ou simplesmente inexistentes), devido à limitação de recursos financeiros, equipamentos e de pessoal. Por conta desta dificuldade tem se procurado definir um conjunto de indicadores ambientais prioritários para que sejam utilizados como uma base comum para medir os níveis do desenvolvimento sustentável. No Brasil, apenas em 2003, o IBGE lançou o seu trabalho "Indicadores de Desenvolvimento Sustentável” (2003), tentando fornecer uma base de dados coletados em outras fontes para a construção de indicadores específicos.

\section{Referências}

AZAR, C.; HOLMBERG, J.; LINDGREN, K. Socio-ecological indicators for sustainability. Ecological Economics, Amsterdam, v. 18, n. 2, p. 89-112, 1996

BOSSEL, H. Indicators for sustainable development: theory, method, applications. Manitoba: International Institute for Sustainable Development - IISD, 1999.

BRAGA, T. M. et al. Índice de sustentabilidade municipal: o desafio de mensurar. Belo Horizonte: UFMG/ Cedeplar, 2003. (Texto para discussão, 225).

COBB, C.; GOODMAN, G. S.; WACKERNAGEL, M. Why bigger isn't better: the genuine progress indicator - 1999 update. San Francisco, CA: Redefining Progress, 1999.

CSD. Indicadores de desarrollo sostenible: marco y metodologías. New York, NY: UN Comisión sobre el Desarrollo Sostenible de las Naciones Unidas, 1996.

DALY, H. E.; COBB JR, J. B. Para el bien comun: reorientando la economia hacia la comunidad, el ambiente y un futuro sostenible. México, DF: Fondo de Cultura Económica, 1989.
HAMILTON, K. Measuring sustainable development, genuine savings. [S.l.]: OECD, 2001. Paper prepared for OECD Round Table on Sustainable Development, 31 May 2001. Disponível em: <http://www.oecd.org/ dataoecd/21/12/2430203.pdf $>$. Acesso em: 3 maio 2004.

IBGE - Instituto Brasileiro de Geografia e Estatística. Indicadores de desenvolvimento sustentável. Rio de Janeiro, 2003.

OECD - Organisation for Economic Co-operation and Development. OECD core set of indicators for environmental performance reviews. Paris, 1993.

OECD - Organisation for Economic Co-operation and Development. Towards sustainable development: environmental indicators. Paris, 1998.

PREFEITURA DO MUNICÍPIO DE SÃo PAULO. Secretaria Municipal do Verde e do Meio Ambiente. GEO cidade de São Paulo: panorama do meio ambiente urbano. Brasília, DF: PNUMA, 2004.

QUIROGA-MARTINEZ, R. (2003) Los indicadores de desarrollo sostenible: estado del arte. Curso-Taller Indicadores de Desarrollo Sostenible para América Latina y el Caribe. Santiago, sede de CEPAL, 2 al 6 de junio 2003.

SUSTAINABLE SEATTLE. Indicators of sustainable community 1998. Seattle, WA, 1998.

VITALIS, V. Measuring what?: roundtable on sustainable development. Paris: OECD, 20o1. Disponível em: <http://www.oecd.org/oecd/pages/document/ displaywithoutnav/o,3376,FR-document-notheme-1no-no-89o9-o,oo.html>. Acesso em: 30 jun. 2004.

WACKERNAGEL, M. et al. Ecological footprints of nations: how much nature do they use? how much nature do they have? Veracruz, Mexico: Centro de Estudios para la Sustentabilidad, 1997. Disponível em: $<$ http://www.ecouncil.ac.cr/rio/focus /report/english/ footprint/>. Acesso em: 1 de jul. 2003.

WACKERNAGEL, M.; REES, W. E. Our ecological footprint: reducing impact on the earth. Gabriola Island, Canada: New Society, 1996.

WWF - World Wildlife Fund. Living planet report 2002. Brussels, 2002.

Recebido em: 18/04/2005

Aprovado em: 13/12/2005 